\title{
Blood pressure reactions to the cold pressor test and the prediction of ischaemic heart disease: data from the Caerphilly Study
}

\begin{abstract}
Douglas Carroll, George Davey Smith, Gonneke Willemsen, David Sheffield, Peter M Sweetnam, John E J Gallacher, Peter C Elwood
\end{abstract}

\begin{abstract}
The prognostic significance of the cold pressor test for cardiovascular disease remains a matter of controversy. ${ }^{1}$ Only two studies have specifically tackled the issue of whether large blood pressure reactions to brief hand immersion in cold water are associated with increased risk for coronary heart disease. In one, the magnitude of diastolic reactions to the cold pressor test was reported to be the most significant single predictor of 20 year incident coronary heart disease in a sample of 279 middle aged men. ${ }^{2}$ In the other, however, neither systolic or diastolic reactions to cold pressor were related to coronary heart disease in a sample of 905 ex-medical students followed up for 24-40 years. ${ }^{3}$ The administration of the cold pressor test to participants in the Caerphilly Collaborative Heart Disease Study ${ }^{4}$ provided an opportunity to help resolve matters.
\end{abstract}

Participants, methods, and results

Details of the methods of baseline and follow up data collection in the Caerphilly studies have been reported previously. ${ }^{4}$ Potentially useable data were available for 1991 men. However, for 498 of them various problems arose during the cold pressor test, such as equipment malfunction, failure to comprehend or follow instructions, or insufficiently lengthy hand immersion. This left an effective sample of 1493 , with an average age at entry of 56.8 years (SD 4.5) and an average body mass index of $26.5 \mathrm{~kg} / \mathrm{m}^{2}$ (SD 3.5). Each participant was required to immerse his right hand to just above wrist level for one minute in $3^{\circ} \mathrm{C}$ water. Blood pressure was recorded, using a Copal UA-231 automatic sphygmomanometer, just before hand immersion as an index of baseline blood pressure. Forty seconds into hand immersion another reading was started; this permitted a cold pressor blood pressure determination before the end of the minute of immersion. For a cold pressor reading to be acceptable, the measurement had to be completed while the participant's hand was fully immersed. Systolic and diastolic blood pressure reactions to the cold pressor were computed in each case as the numerical difference between the cold pressor and baseline pressure readings. The cold pressor tests were carried out between 1984 and 1988.

Incident ischaemic heart disease was determined nine years later as either death with a 410-414 ICD coding, or a clinical event meeting the standard WHO criteria for acute myo- cardial infarction, or the appearance of major or moderate $\mathrm{Q} / \mathrm{QS}$ waves on ECG when there were no Q/QS waves either on recruitment in 1979-1983 or at the time of cold pressor testing in 1984-88.

Both systolic and diastolic blood pressure increased significantly during hand immersion $(p<0.001$ in each case). The overall average reactions to cold pressor were $24.1 \mathrm{~mm} \mathrm{Hg}$ (SD 15.8) systolic and $12.2 \mathrm{~mm} \mathrm{Hg}$ (SD 9.5) diastolic. The predictive significance of these blood pressure reactions was examined using logistic regression, first for incident ischaemic heart disease and then for ischaemic heart disease mortality. Age was always entered at the outset. At nine year follow up, 161 new cases of ischaemic heart disease were recorded. Neither systolic nor diastolic reactions to the cold pressor predicted ischaemic heart disease. Table 1 presents the average systolic and diastolic blood pressure reactions for men with and without ischaemic heart disease. The absolute levels of both systolic and diastolic blood pressure during hand immersion did predict disease status $(p<0.001$ and $p=0.003$, respectively). However, so too did baseline systolic and diastolic blood pressure $(p<0.001$ and $\mathrm{p}=0.001$, respectively), and in stepwise models examining both baseline and cold pressor blood pressure levels, only the baseline value entered the equation. During the nine year follow up period 76 of the participants died of ischaemic heart disease (ICD codes 410-414). Neither systolic nor diastolic reactions to the cold pressor test predicted mortality, nor did the absolute levels of systolic and diastolic blood pressure during hand immersion.

\section{Comment}

These results raise serious doubts as to whether blood pressure reactions to the cold pressor test predict incidence of and death from ischaemic

Table 1 Average (SD) systolic and diastolic blood pressure reactions in $\mathrm{mm} \mathrm{Hg}$ to the cold pressor test for men who developed major ischaemic heart disease during the nine year follow up

\begin{tabular}{lll}
\hline & $\begin{array}{l}\text { Systolic blood } \\
\text { pressure }\end{array}$ & $\begin{array}{l}\text { Diastolic } \\
\text { blood } \\
\text { pressure }\end{array}$ \\
\hline $\begin{array}{l}\text { Men developing ischaemic heart } \\
\text { disease }\end{array}$ & $24.2(17.0)$ & $12.4(8.9)$ \\
$\begin{array}{l}\text { Men not developing ischaemic } \\
\text { heart disease }\end{array}$ & $24.1(15.6)$ & $12.2(9.5)$ \\
\hline
\end{tabular}


heart disease. Considered along with our previous findings, that cold pressor reactions did not predict future blood pressure status, ${ }^{1}$ the present analyses suggest that the cold pressor test may be of little clinical use in older populations.

1 Carroll D, Davey Smith G, Sheffield D, et al. Blood pressure reactions to the cold pressor test and the prediction of future blood pressure status: data from the Caerphilly study. F Hum Hypertens 1996;10:777-80.
2 Keys A, Taylor HL, Blackburn H, et al. Mortality and coronary heart disease among men studied for 23 years. Intern Med 1971;128:201-14.

3 Coresh J, Klag MJH, Mead LA, et al. Vascular activity in young adults and cardiovascular disease: a prospective study. Hypertension 1992;19 (suppl 11):218-23.

4 Caerphilly and Speedwell Collaborative Group. Caerphilly and Speedwell collaborative heart disease studies $\mathcal{F}$ Epidemiol Community Health 1984;38:836-44.

5 Yarnell JWG, Bainton D, Sweetnam PM, et al. Fibrinogen, viscosity and white cell count are major risk factors for viscosity and white cell count are major risk factors for
ischaemic heart disease: the Caerphilly and Speedwell Collaborative Heart Disease Studies. Circulation 1991;83:83644 . 